Check for updates

Cite this: RSC Adv., 2022, 12, 5769

Received 9th November 2021 Accepted 3rd February 2022

DOI: $10.1039 / d 1 r a 08212 d$

rsc.li/rsc-advances

\section{Comments on "Removal of methylene blue dye using nano zerovalent iron, nanoclay and iron impregnated nanoclay - a comparative study" by M. M. Tarekegn, R. M. Balakrishnan, A. M. Hiruy and A. H. Dekebo, RSC Adv., 2021, 11, 30109}

\begin{abstract}
Jean-Claude Bollinger, (iD *a Hai Nguyen Tran (iD ${ }^{\text {bc }}$ and Eder C. Lima (iD)
The study mentioned in the title of this comment paper contains some calculations/results that disagree with some basic chemistry concepts. These misleading calculations include (i) both kinetic and isotherm modelling through linear equations, and (ii) calculating the thermodynamic parameters for the adsorption processes. Thus, we run through the correct way to make these calculations. In our opinion, it is very confusing to continue to disseminate erroneous methods as applied in the original paper.
\end{abstract}

\section{Introduction}

Recently, the above-cited paper (hereafter also called 'the original paper') was published in RSC Advances by Tarekegn et al. ${ }^{1}$ The objective of the paper is ambitious, and this detailed study of the preparation and characterization of nZVI, nanoclay and iron-impregnated nanoclay, and their use for adsorbing the methylene blue (MB) dye in batch mode, is worthy of interest.

Unfortunately, some shortfalls limit the scientific value of this study. Indeed, due to many years experience in adsorption studies, both as authors and reviewers, we consider that several parts of the modelling methods and their subsequent discussions should be reconsidered.

\section{Discussion}

Here we will mainly focus on subsection '3.4 Adsorption isotherms, kinetics and thermodynamics’ in the original paper, ${ }^{1}$ where several fundamental errors can be discovered.

\subsection{Adsorption experiments}

In their original paper, the authors should add information about the number of replicates for all experiments (including preparation of the solid adsorbent material, and MB

${ }^{a}$ Groupement de Recherches Eau, Sol, Environnement, Faculté des Sciences, Université de Limoges, 87060 Limoges, France.E-mail:jean-claude.bollinger@unilim.fr

${ }^{b}$ Institute of Fundamental and Applied Sciences, Duy Tan University, Ho Chi Minh City, 70000, Vietnam. E-mail: trannguyenhai@duytan.edu.vn

${ }^{c}$ Faculty of Environmental and Chemical Engineering, Duy Tan University, Da Nang, 550000 , Vietnam

${ }^{d}$ Institute of Chemistry, Federal University of Rio Grande do Sul (UFRGS), 91501-970, Porto Alegre, RS, Brazil. E-mail: eder.lima@ufrgs.br concentration determination), hence the corresponding standard deviation. Then in all figures the experimental data points should contain their respective error bars.

Moreover, the MB 'removal (adsorption) efficiency' given according to the original eqn (3), i.e.:

$$
\mathrm{RE}=\left(1-\frac{C_{\text {final }}}{C_{\text {initial }}}\right) \times 100
$$

where initial and final $\mathrm{MB}$ concentrations are in $\mathrm{mg} \mathrm{L}^{-1}$, as a characteristic measure for the adsorption process, is useful from a practical point of view; however, it only makes sense if the initial concentration is given. Thus, it would be better to directly introduce the amount of $\mathrm{MB}$ removed at time $t$ per gram of adsorbent $\left(\mathrm{mg} \mathrm{g}^{-1}\right)$

$$
q_{t}=\frac{\left(C_{0}-C_{t}\right) \times V}{m}
$$

where $C_{0}\left(\mathrm{mg} \mathrm{L}^{-1}\right)$ is the initial $\mathrm{MB}$ concentration, $C_{t}\left(\mathrm{mg} \mathrm{L}^{-1}\right)$ its concentration at time $t(\mathrm{~min}), m(\mathrm{~g})$ the dry mass of the chosen adsorbent and $V(\mathrm{~L})$ the volume of MB solution.

\subsection{Kinetic modelling}

Firstly, from a logical point of view, kinetics should be realized before isotherms to select the best contact time. In the original paper, the authors used the linear regression method to calculate the parameters of the kinetic models, where pseudo-firstorder, or the so-called Lagergren equation (PFO) and pseudosecond-order (PSO) kinetics equations are written as the original eqn (19) and (20), respectively:

$$
\begin{gathered}
\ln \left(q_{\mathrm{e}}-q_{t}\right)=\ln q_{\mathrm{e}}-k_{1} t \\
\frac{t}{q_{t}}=\frac{t}{q_{\mathrm{e}}}+\frac{1}{k_{2} q_{\mathrm{e}}^{2}}
\end{gathered}
$$


However, several studies ${ }^{2,3}$ have demonstrated that non-linear regression is more appropriate to obtain the parameters of kinetic models, rather than linear regression. This shortcoming is because transformations of non-linear equations to linear forms implicitly alter their error structure and may also violate standard least-squares error variance and normality assumptions. In this setting, the non-linear method provides a mathematically rigorous method for determining model parameter values; fortunately, we all now have easy access to computer programs with non-linear least-squares (NLLS) adjustments, to be applied in the present case in place of linear regression analyses, with the full non-linear $q_{t}=f(t)$ forms of PFO and PSO equations, respectively:

$$
\begin{gathered}
q_{t}=q_{\mathrm{e}}\left[1-\exp \left(-k_{1} t\right)\right] \\
q_{t}=\frac{k_{2} q_{\mathrm{e}}{ }^{2} t}{1+q_{\mathrm{e}} k_{2} t}
\end{gathered}
$$

Lima et al., ${ }^{3}$ in a study with 252 kinetic results, showed that the values of $k_{1}$ and $k_{2}$ obtained from linear fitting do not match the values of these parameters obtained by non-linear fitting. The value of $q_{\mathrm{e}}$ obtained by a linear approach of the PSO model matched with the value of non-linear fitting. This is the main reason that authors insist on using linear fitting for kinetic treatment. Also, using the linear fitting, the 252 experiments were better fitted to a linear PSO model. However, when nonlinear fitting was utilized, more than $50 \%$ of the kinetic results were better fitted to a non-linear PFO model. Therefore, this study demonstrates that high values of $R^{2}$ in linear fitting are not a good statistical tool to establish a kinetic model.

Consequently, the content of the original Table 4 should be changed to new values calculated from the NLLS method.

\subsection{Isotherm modelling}

Similarly, in the original paper, isotherm data have been modelled with the linear forms of Langmuir and Freundlich equations (original eqn (17) and (18), respectively):

$$
\begin{gathered}
\frac{C_{\mathrm{e}}}{q_{\mathrm{e}}}=\frac{C_{\mathrm{e}}}{q_{\max }}+\frac{1}{K_{\mathrm{L}} q_{\max }} \\
\log \left(q_{\mathrm{e}}\right)=\log K_{\mathrm{F}}+\frac{1}{n_{\mathrm{F}}} \log \left(C_{\mathrm{e}}\right)
\end{gathered}
$$

Of course, here also the non-linear forms are better, ${ }^{4}$ written as:

$$
\begin{gathered}
q_{\mathrm{e}}=\frac{Q_{\max } K_{\mathrm{L}} C_{\mathrm{e}}}{1+K_{\mathrm{L}} C_{\mathrm{e}}} \\
q_{\mathrm{e}}=K_{\mathrm{F}} C_{\mathrm{e}}{ }^{1 / n_{\mathrm{F}}}
\end{gathered}
$$

Therefore, we suggest that the original Fig. 20 and 21 could be deleted and changed into the direct isotherm curves $q_{\mathrm{e}}=$ $f\left(C_{\mathrm{e}}\right)$, allowing one to obtain information about the formation of a plateau. Moreover, the parameters given in the original Tables
3 and 4 should be recalculated under the NLLS method. Then, the authors could better discuss their results as a comparison of the three solid adsorbents is concerned.

\subsection{Thermodynamic parameters}

The calculation of the thermodynamic parameters for $\mathrm{MB}$ adsorption onto each solid adsorbent was done from the classical thermodynamic relationships (eqn (22)-(24) in the original paper). However, contrary to the assertion of the authors of the original paper, $K_{\mathrm{e}}$ from their eqn (21) cannot be considered as 'the adsorption equilibrium constant'; indeed, this is the distribution coefficient

$$
K_{\mathrm{e}}=\frac{q_{\mathrm{e}}}{C_{\mathrm{e}}}
$$

whose unit is

$$
\frac{\left.\mathrm{mg} \mathrm{g}^{-1} \text { (of adsorbent }\right)}{\mathrm{mg} \mathrm{L}^{-1}(\text { of solution })}=\frac{\mathrm{L}}{\mathrm{g}(\text { of adsorbent })}
$$

Thus, $K_{\mathrm{e}}$ cannot be introduced in place of $K_{\mathrm{Eq}}^{0}$ within the definition of the standard Gibbs energy

$$
\Delta G^{\circ}=-R T \ln \left(K_{\mathrm{Eq}}^{0}\right)
$$

Because one can only take the logarithm of a dimensionless parameter, moreover, when calculating an equilibrium constant, the only unit for the amount of substance should be $\mathrm{mol} \mathrm{L}^{-1}$ (not $\mathrm{g}$ or $\mathrm{mg}$ or any other) to make the logarithm of the so-called 'thermodynamic equilibrium constant' $K_{\mathrm{Eq}}^{0}$ unitless. Although this should be a well-known topic, ${ }^{4-7}$ it is too often forgotten.

Therefore, it is impossible to introduce the distribution coefficient $K_{\mathrm{e}}$ to calculate the thermodynamic parameters.

\subsection{The Langmuir constant}

We have another puzzling point to note about the calculation of these thermodynamic parameters. A net discrepancy appears between the values of the Langmuir adsorption constant $K_{\mathrm{L}}$ in Table 3 (probably at $T=303 \mathrm{~K}$ ) and in Table 5; moreover, the data points in Fig. 22 do not seem to be consistent with this Table 5.

Again, $K_{\mathrm{L}}$ (with its unit in $\mathrm{L} \mathrm{mg}^{-1}$ of adsorbate) cannot allow the calculation of the Gibbs energy for the adsorption process directly; it should be transformed by calculating the corresponding (dimensionless) thermodynamic Langmuir constant $K_{\mathrm{L}}^{0}$ To do this calculation, we kindly suggest the use of the following relationship: $:^{5,6,8}$

$$
K_{\mathrm{L}}^{0}=\frac{1000\left(\mathrm{mg} \mathrm{g}^{-1}\right) \times K_{\mathrm{L}}\left(\mathrm{L} \mathrm{mg}^{-1}\right) \times M_{\mathrm{w}}\left(\mathrm{g} \mathrm{mol}^{-1}\right) \times C^{0}}{\gamma}
$$

This is eqn (12) in Mouni et al. ${ }^{9}$ (quoted as ref. 80 in the original paper) where $M_{\mathrm{MB}}=319.85 \mathrm{~g} \mathrm{~mol}^{-1}$ is the $\mathrm{MB}$ molar mass, $C^{0}=1 \mathrm{~mol} \mathrm{~L}^{-1}$ corresponding to the solution standard state, and the factor 1000 allows converting $\mathrm{g}$ to $\mathrm{mg}$; and 
assuming the activity coefficient of the MB dye solution as unitary for infinite dilution. ${ }^{8}$

Now, one can easily and rigorously calculate the Gibbs energy $\Delta G^{\circ}$, and obtain the other thermodynamic parameters $\Delta H^{\circ}$ and $\Delta S^{\circ}$ from data at various temperatures according to the non-linear van't Hoff relationship: ${ }^{\mathbf{8 1 0}}$

$$
\begin{gathered}
\Delta G^{\circ}=-R T \ln \left(K_{\mathrm{L}}^{0}\right) \\
K_{\mathrm{L}}^{0}=\exp \left[\frac{\Delta S^{\circ}}{R}-\left(\frac{\Delta H^{\circ}}{R}\right) \frac{1}{T}\right]
\end{gathered}
$$

In any case, the comments in the original paper about the sign, the magnitude and the significance of the thermodynamic parameters should be moderated with reference to Salvestrini et $a .^{5}$

\section{Conclusion}

It is of course important to emphasize that this 'Comment' paper should not discredit the work by Tarekegn et al. ${ }^{1}$ On the contrary, the original published article is really interesting and contributes to scientific knowledge; however, as indicated above, some corrections should be conducted and published by the original authors. Furthermore, the present authors hope that these comments will be read in the spirit in which they are intended; that is, constructive criticism to produce a better final scientific paper, and to avoid the dissemination of undesirable and overlooked mistakes into the scientific literature, as discussed for example in several recent critical papers, here cited within the Discussion section.

\section{Author contributions}

All authors have made equal contributions to this paper.

\section{Conflicts of interest}

There are no conflicts to declare.

\section{References}

1 M. M. Tarekegn, R. M. Balakrishnan, A. M. Hiruy and A. H. Dekebo, RSC Adv., 2021, 11, 30109.

2 J.-P. Simonin, Chem. Eng. J., 2016, 300, 254-263.

3 E. C. Lima, F. Sher, A. Guleria, M. R. Saeb, I. Anastopoulos, H. N. Tran and A. Hosseini-Bandegharaei, J. Environ. Chem. Eng., 2021, 9, 104813.

4 H. N. Tran, S.-J. You, A. Hosseini-Bandegharaei and H.-P. Chao, Water Res., 2017, 120, 88-116.

5 S. Salvestrini, V. Leone, P. Iovino, S. Canzano and S. Capasso, J. Chem. Thermodyn., 2014, 68, 310-316.

6 X. Zhou and X. Zhou, Chem. Eng. Commun., 2014, 201, 14591467.

7 J.-C. Bollinger, Environ. Pollut., 2019, 261, 113824.

8 E. C. Lima, A. Hosseini-Bandegharaei, J. C. Moreno-Piraján and I. Anastopoulos, J. Mol. Liq., 2019, 273, 425-434.

9 L. Mouni, L. Belkhiri, J.-C. Bollinger, A. Bouzaza, A. Assadi, A. Tirri, F. Dahmoune, K. Madani and H. Remini, Appl. Clay Sci., 2018, 153, 38-45.

10 E. C. Lima, A. A. Gomes and H. N. Tran, J. Mol. Liq., 2020, 311, 113315. 